\title{
Improvement Model for Strategic Planning in the Frame of Earned Value Using Mathematical Clustering
}

\author{
Sanaz Shahri ${ }^{1}$, Hamed Fazlollahtabar, ${ }^{3,4, *}$, Iraj Mahdavi ${ }^{2}$, Zeinolabedin Rahmani ${ }^{1}$ \\ ${ }^{1}$ Department of Management, Payam-e-Noor University, Sari, Iran \\ ${ }^{2}$ Department of Industrial Engineering, Mazandaran University of Science and Technology, Babol, Iran \\ ${ }^{3}$ Faculty of Industrial Engineering, Iran University of Science and Technology, Tehran, Iran \\ ${ }^{4}$ Niroogostar Energy Optimization Research Group, Tehran, Iran \\ *Corresponding Author: hfazl@iust.ac.ir
}

Copyright $@ 2013$ Horizon Research Publishing All rights reserved.

\begin{abstract}
This study is a strategic planning improvement Model in framework of Earned Value using mathematical clustering. For this purpose, providing methods and strategies used in the mathematical clustering techniques to provide better and more effective organizational strategies which are the main objective of this research are examined. Specific research question includes the possibility to improve the strategic planning framework for business value by using the clustering approach. A case study is conducted to validate the proposed methodology. The data collected through interviews with experts and managers in the organization and documents were used to prepare the strengths, weaknesses, opportunities and threats factors. For analysis and comparison of the results the earned value techniques was performed.
\end{abstract}

Keywords Strategic Planning, Earned Value, Mathematical Clustering

\section{Introduction}

Strategic planning is difficult but rewarding. It provides road maps to guide an organization and ways to track progress and to measure success. As a management tool, it can help minimize surprises and make the organization resilient to such surprises as do occur. Information technology planning must be founded upon an overall business strategic plan and take into account the need to understand new technology, processes, methods, and products-and to translate them into workable system solutions [1].

Strategic management is the art of managing organizations in maximizing the potential of achieving business objectives. It attempts to organize qualitative and quantitative information, allowing effective decisions to be made under different conditions of uncertainty. It consists of three distinct stages: strategy formulation, strategy implementation, and strategy evaluation. The well-known
SWOT (strength, weakness, opportunity and threat) analysis and QSPM (Quantitative Strategic Planning Matrix) fit into the first stage and have been proven to be excellent tools for deciding among feasible alternative strategies [2]. In the SWOT analysis, however, deciding on relative importance of various facts, figures, trends, and data among feasible alternative strategies is critical in arriving at solutions that provide major competitive advantages to a given firm. SWOT analysis is a tool in strategy formulation by identifying the strengths, weaknesses, opportunities and threats of a given organization. Several studies have employed the SWOT analysis with the goal of improving the classical strategic planning and management methods[3].

Before working out their final strategic plan, managers must consider several feasible alternatives and contemplate various factors behind each of them. It is a very complicated task to select the best strategic plan. At present, strategic planning approaches with procedural structures are usually employed [4].They guide managers in establishing each level of the strategic plan so that a strategy can be completely constructed. However, issues such as which items must be discussed in each level of the plan and how to connect the various levels of the plan have not been clearly described. For example, the portfolio matrix approach [5] fails to establish the linkage between the factors that influence the internal and external components of a strategic business unit (SBU) and the factors that influence the whole of the SBU. Difficulties also arise in implementing the evaluation step of the strategic planning process. Since, the managers' past experience is needed to help evaluate the whole circumstance of an SBU using internal and external factors related to the business unit, someone without past experience cannot perform the evaluation. Furthermore, it is often impossible to describe the evaluation process in detail, either verbally or numerically and, hence, the transfer of the knowledge and experiences required for evaluating and selecting strategies usually takes a long time[6].

Clustering is defined as a mathematical technique designed for revealing classification structures in the data 
collected in the real world phenomena [7]. In other words, the main purpose of clustering is to find out the classification structure of the data. The term classification was defined by a researcher as ordering or arranging objects into groups or sets on the basis of their similarities or relationships. The purpose of classification is formulated as to shape and keep knowledge; to analyze the structure of a phenomenon and to relate different aspects of a phenomenon in question to each other [7]. According to these definitions, classification can be defined as simplifying a complex structure by ordering or arranging objects into groups according to their similarities or relationships without losing significant information about the data. The clustering techniques depicted in the literature can be mainly categorized under two headings, namely supervised and unsupervised classification techniques. In supervised classification, membership of data points which can illustrate the general structure of the group is required in order to derive the classification rules. On the other hand, there is no rule for initiation of unsupervised classification.

Cluster analysis is used for clustering a dataset into groups of similar individuals. It is one of the major tasks in pattern recognition. Since Zadeh[8] proposed fuzzy sets that use the idea of partial membership described by a membership function, many fuzzy clustering methods have been introduced, for instance [9].

To evaluate the financial performance of a company or make a business decision for an enterprise, a large amount of data needs to be processed in advance. To analyze the data, one of the most important techniques is clustering (Wang and Lee, 2008. Generally, information of a data is presented as a data sequence, such as data for financial ratios [10], time series, sales variations, etc. Financial ratios, for instance, are usually served as evaluation criteria for the financial performance of a company. However, some financial ratios have similar patterns, and thus it will be inefficient to take all the financial ratios into consideration. To avoid re-evaluation of similar financial ratio sequences, the data sequences are partitioned into clusters. After clustering, the characteristics of the financial ratios in the same cluster will be more similar, whereas the inter-cluster characteristics will be less similar[11].Numerous clustering methods have been proposed. The clustering methods include cluster analysis, discriminant analysis, factor analysis, principal component analysis [12], grey relation analysis, and K-means[13]. Cluster analysis, discriminant analysis, factor analysis and principal component analysis are commonly applied to classic statistical problems, such as for a large sample or long-term data. To deal with a small sample or short-term data, grey relation analysis and K-means are preferred. Since the partitioning result depends highly on the clustering method adopted, applying an appropriate clustering method is essential for data sequence partitioning. Based on the patterns of data sequences, we propose a clustering system which is originally constructed on a fuzzy binary relation. A fuzzy binary relation roots in the variation between any two data sequences and satisfies a compatible relation. However, items within different clusters may overlap when a fuzzy relation merely satisfies a fuzzy compatible relation. To solve the problem, additional mechanisms (Wang and Lee, 2008) are needed as well for partitioning. Applying the max-min transitive closure, for example, is one of the most practical methods to transfer a fuzzy compatible relation into a fuzzy equivalence relation[14, 15]. In this paper, we also apply the max-min transitive closure to serve as an additional mechanism. That is to say, our method is based on a fuzzy compatible relation and the max-min transitive closure to partition data sequences into clusters.

\section{Statement of the Problem}

Strategic planning, which is a dynamism motion to place the organization in better than a situation that only reacts to the evident happenings. Goodraham[16] adapts the strategic planning of organization to its environment, creates a ground for achieving the targets, and provides a framework and direction for organization to get the desirable future. The analysis of Swat has proved that is one the most effective tools and has a suitable base to identify the present recognition and plans a method and direction for future actions.

The stages of work include at first, in the desired place, we arrange the first visit to be familiar with organization and to hold a session with senior managers and when the importance of job is clear out for them, and next session includes questions about recognizing the strength points of organization, which will be performed by asking managers of different parts some questions. When the job is done, we identify and set all strength points. Next, through the questions have already been raised (you can use your strengths as well as identifying the strengths and weaknesses can be detected more easily)and asking administrators weaknesses are identified. And similarly, during later meetings, we identify organizational opportunities and threats. In traditional method, managers of organization, choose the intended strategy from identified factors, this method has error because the experts have no similar behavior relate to similar phenomenon. As the SWOT parameters are classified into verbal expressions may be little they can do. After identification of the organization in Swat, a lot of different kinds of organizations, including labor, materials, production process, and the flow of information is available. Due to the high volume of integrated strategies is impossible. Those who present strategy with no attention this point generally forget very crucial points and in other way, their advanced strategies cannot cover the entire organization. This can be seen when the organization is great. To solve this problem we have used clustering. The process we use called hierarchical clustering using the K-Means algorithm. The clustering attempts to divide data into clusters that maximize the similarity between the data within each cluster and the similarity between data from different clusters is minimized. In this 
way, the final clusters based on hierarchical structure of their generality, usually attributed tree. The root node of tree diagram represents the entire data and each leaf represents as a data point to be considered. Thus the objects of intermediate nodes that are close together describe tree diagram altitude generally between each pair or clusters of data points or a point and a given cluster is uttered. Final results of tree diagram levels of clustering results can be achieved. Thus, we have an assortment of Swat. The classification task is facilitated investment strategies and the formulation of strategies and action takes place. So, using the values gained from an activity, which funds the work done on a project until a specified date, and how it should be spent on the project's performance, the use of project resources, show each strategy were identified, and rated the importance of each of them is determined using this technique. This means that we determine in which areas are located, so they showed us a little of 1-100 to determine the extent of their use.

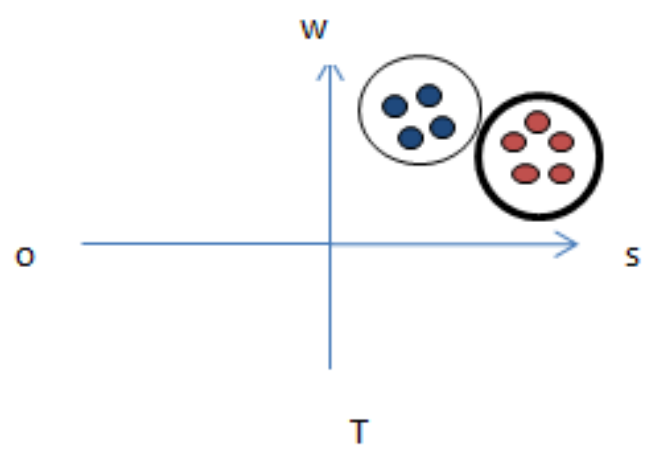

Figure 1. Clustering the resulted agents

Using this technique has many advantages, including the strategy for the organization if the organization has identified strategies look similar but are different in nature (i.e., the Director may, these are two in place of the use of) The strategy this technique It also measures the degree of importance and defines their distinction. Also at any time if organizational circumstances and factors affecting the organizational change, this techniqueis a suitable method to identifythem. Also, it helps managers to improve the results of the procedure and ease of use in decision-making.

Now, the identified strategies are prioritized by achieved quantity values, we can design short and long term operational programs and finally the effectiveness and profitability of exploited strategies compare to organizational traditional method from the viewpoint of experts and managers of organization and executives of the survey are analyzed and the results are reported.

\subsection{Research Question and Assumptions}

The main research question and assumptions are followed here:

Is it possible to improve the strategic planning approach in the context of business value using mathematical clustering methods are there?

Research assumptions

1) The values and parameters of strategic planning are significantly related.

2) Mathematical Clustering and Earned Value have meaningful relationships.

\section{Modeling the Problem}

\subsection{SWOT Analysis}

SWOT analysis has proved to be an effective tool and has constituted a suitable baseline to diagnose current problems and to sketch future action lines. However, pinpointing SWOT factors is too often imprecise listing or an incomplete qualitative examination of factors. Thus, this gives rise to the need of more efficient use of SWOT [17]. The multi-criteria methods are considered the most appropriate analytical method for development of a method with SWOT [18]. SWOT analysis has resulted in a successful tool when experts' discussion and interaction is needed and a set of strategies should be agreed upon. This activity is important because it defines the way the organizations are managed and the criteria under which strategies are evaluated.

SWOT analysis is a commonly used tool for analyzing internal and external environments in order to attain a systematic approach and support for a design situation. There is no standard list of factors that apply for all construction organizations because of the specificity of each set. However, strengths tend to relate to the competitive advantages and other distinguishing competencies, which can be exploited by the organization on the market. Weaknesses are limitations which hinder the process of an organization in a certain direction. Opportunities relate, for example, to the technology enabled advantages that can be obtained by the uptake of IT. Threats relate to an array of macroscopic and microscopic problems that exist or may arise which can potentially jeopardize the successful implementation of proposed IT projects.

If used correctly, SWOT can provide a good basis for successful IT implementation strategy formulation. When undertaking SWOT, the analysis lacks the possibility of comprehensively appraising the strategic decision-making situation; merely pinpointing the number of factors in strength, weakness, opportunity or threat groups [19]. In addition, SWOT includes no means of analytically determining the importance of factors or of assessing the fit between SWOT factors and decision alternatives. Thus, it can be concluded that the result of SWOT analysis is too often only a superficial and imprecise listing or an incomplete qualitative examination of internal and external factors.

\subsection{SWOT Factors}


Central to this step is the incorporation of the scale of values of the corporate management of the organization (e.g. objectives, perceptions, beliefs and challenges). This activity is important because it defines the way the organization is managed and the criteria under which strategies are evaluated. Keeping in mind the scale of values of the organization's corporate management, the industry needs to undertake an external and internal analysis. The former examines the environment in which the organization is participating to study the potential opportunities and threats whereas the latter identifies the weaknesses and strengths of the organization. Combining the results of the external and internal analysis and taking into account the scale of values, the Strengths, Weaknesses, Opportunities, and Threats (SWOT) factors are identified. Figure 2 represents an environmental SWOT analysis.

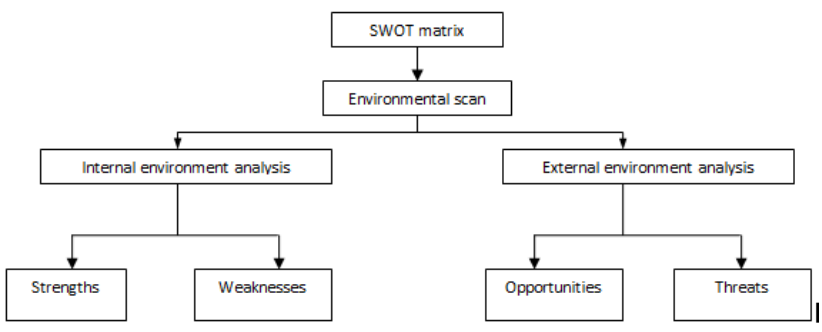

Figure 2. Environmental SWOT Analysis

\subsection{External Environment Analysis}

The changing business environment and increased IT capabilities are translating into more focused emphasis on strategic integration. Increased global competition on one hand and availability of communication-tools on the other, have enhanced opportunities for design and construction organizations to establish joint ventures, partnering and long term relationships with clients and/or suppliers. Also, integrations between planning, design and construction organizations are gaining increased attention from practitioners and researchers alike focusing upon increased productivity and improved quality of construction. Therefore, the main purpose of this analysis is to identify IT enabled integration and alliancing opportunities/threats. It is not sufficient though to concentrate the external analysis at the macroscopic level of the industry alone. This is because even at the microscopic level of construction projects, IT spending has grown rapidly with operations and maintenance costs dominating the budget. In addition, an external analysis can capture the dynamic nature of project participants in a large-scale construction project. To better understand the relationship of all components of an IT strategy on construction projects and within strategic business units of an organization, it is helpful to examine the strategy in a systematic way, looking at the various investments, and the tangible as well as intangible returns from these investments.

\subsection{Internal Environment Analysis}

Several researchers have articulated the need to consider how the internal organizational environment is determinant of the strategic IT implementation planning process. For example, the organization's corporate culture can facilitate its strategic IT planning by being congruent with it. The organization's planning and control style, is perhaps in part a function of corporate culture, similarly influences strategic IT implementation planning. Likewise, organizational size, organizational structure (mechanistic vs. organic) and management style (entrepreneurial vs. conservative) may influence strategic IT implementation planning. The primary role of the internal analysis is to identify the weaknesses and strengths of the organization.

Responding to the internal strengths and weaknesses is therefore an essential component of the strategic management process. By collating all the opportunities and threats obtained through external analysis, combined with strengths and weaknesses obtained through internal analysis the organization can undertake SWOT analysis as explained below.

\subsection{K-Means}

Despite its simplicity, this method is a fundamental technique for many other clustering methods (phase clustering) is considered. This is an exclusive and flat. Various forms of this algorithm are presented. But all of them are repetitive routine for a fixed number of clusters, we have the following estimates:

- To obtain points as centers of clusters that belongs to the same average points per cluster.

- To assign each data to a cluster that has the least distance to the cluster center.

The simplicity of this method, the required number of clusters is randomly chosen points. Data regarding the proximity (similarity) to one of these clusters are relatively new, thus resulting clusters. By repeating this procedure can be repeated on each Averaging data centers for clusters of new data to be calculated again. This process continues until the change in the data is not obtained. The following function is as objective function.

$$
J=\sum_{j=1}^{k} \sum_{i=1}^{x}\left\|x_{i}-c_{j}\right\|^{2}
$$

where, \|\| is the criteria of distance between points and cj, the center of cluster $\mathrm{j}$.

The following algorithm is considered as a basic algorithm for this method:

1. At first, $\mathrm{K}$ points as cluster centers are selected parts.

2. Each data center cluster to the cluster that has the least distance to the data, are compared.

3. After all data belonging to one of the clusters is calculated for each cluster, a new point as the center. (Average points belonging to each cluster).

4. Steps 2 and 3 are repeated until the cluster centers do 
not change.

The clustering algorithm is applied in the following manner on a data set consisting of two groups is shown. A group of stars and other data are marked with a circle (a). The first point is selected as the cluster center is shown in red (b). This procedure does not change until reaching to the other, has continued.

As mentioned in previous section after identifying the strengths, weaknesses, opportunities and threats continue using the clustering algorithm is introduced to classify these points we needed to get strategies We derive these categories.

$\mathrm{K}$-Means clustering method is one of the most popular clustering techniques is that the process is repeated. This algorithm is applicable in cases where each side is awarded to only one class. This algorithm is an unsupervised algorithm and a replication data set into k clusters in which the data points were randomly divided and awarded to the clusters. Then for each point, the distance to the cluster center is calculated and the point closest to the cluster belongs. These stages are repeated till other points do not find a place to change.

Features of this algorithm are:

There is always a cluster $\mathrm{k}$

There is always at least one point in each cluster

Hierarchical cluster are suitable since it does not overlap

Each member of a cluster, the other clusters is the least distance to the cluster center.

1. At the beginning, with the initial cluster centers for $z 1$, $\mathrm{z} 2, \ldots, \mathrm{zk}$ of $\mathrm{n}$ points randomly chooses

2. Points of $\mathrm{i}=1,2, \ldots, \mathrm{n}$ are assigned to the cluster of $\mathrm{j}=1,2, \ldots, \mathrm{k}$ if :

$p !=j$ and $p=1,2, \ldots \ldots . . k \quad D\left(z_{j}, x i\right)<D\left(z_{p}, x_{i}\right)$

3. We calculate new clusters of $z *_{1}, z *_{2}, \ldots, z *_{k}$ as follows

$$
i=1,2, \ldots k \sum_{j \in c} x_{j} *_{1}=1 / n
$$

4. If $\mathrm{z}_{\mathrm{j}} \mathrm{Z} *_{\mathrm{i}}=$, it ends, otherwise, it returns to stage 2 .

In order to measure the distance between the clusters, the metric Mincowoski Formula used is given below:

$$
\mathrm{d}_{\mathrm{p}}\left(\mathrm{x}_{\mathrm{i}}, \mathrm{x}_{\mathrm{j}}\right)=\left[\sum_{\mathrm{k}=1}^{\mathrm{d}}\left\|\mathrm{x}_{\mathrm{i}, \mathrm{k}}-\mathrm{x}_{\mathrm{j}, \mathrm{k}}\right\|^{\mathrm{p}}\right]^{1 / \mathrm{p}}
$$

\section{Case Study}

Strategic planning is a task that can be done once and stay quiet for a while, but the process is an activity, the characteristics such as continuity, continuity, and comprehensiveness is dynamic. Thus, the managers to revive organization, planning and design are continually being modified and this is a doable task and not broken. Conventional methods are used in this analysis, the use of expert opinion is wrong because they have always appeared in the same phenomena are similar. One of the most appropriate tools that we can identify the present problems and plan a way for future actions is to use SWAT. The current methods that are used in this analysis, like using the opinions of experts have error, because they have no similar opinions about similar phenomenon. So in this research, using the SWAT method, we identify the inner and outer environments of organization and then identify all agents including strength, weakness points, opportunities and organizational threats and using the mathematical clustering approach, we cluster the identified agents to put the similar and different agents in different clusters and considering the classifications can determine the intended organizational strategies. Finally, using earned value techniques, strategies and priorities, we compare them with traditional strategy to express the advantages and benefits of our method.

\subsection{Introduction of the Company}

Cement plant, located $2.5 \mathrm{~km}$ south of the town of Neka, located $20 \mathrm{~km}$ from the city of Sari, Mazandaran Province in 90 acres of land and is located near the village of Ablo. Naturally, this plant owns the most beautiful situation among all cement plans in country and its primary mineral materials are lime and clay in jungles of Mazandaran and near the river of Neka. Stakeholders of this plant are Cement of Fars and Khuzestan 17\%, Cement of North $25.5 \%$, Kerman Cement $20 \%$, the Industry \& Mining Investment Company $16.9 \%$, Iran Cement Industries Development and Investment Company $9.7 \%$, the National Development Investment Company $4.8 \%$.

\subsection{Analysis of Internal Factors}

After reviewing the organization of the study, to identify the strengths and weaknesses of the organization affected by the costs, product quality, human resources (in terms of education, employment records) quality control systems, how access to information technology, education, information technology, sales and export ... are paid and most of them are described below.

\subsection{Analysis of External Factors}

The factors affecting the organization, mode of study, to identify opportunities and threats that affect organizational factors on customers, competitors, political and economic factors, and we finally evaluate the data obtained from the institutional environment, most of them are described below.

\subsection{Evaluation of Internal Factors}

Based on studies done in the study area on the company's 47 strong points and 40 weak points are obtained (as shown in table 1 given in Appendix). Based on the outcome of managers and employees, in interviews, the following matrix is obtained. In this matrix, internal strategic factors, weighting and rating each of their strengths and weaknesses 
are observed. The column internal factors, we've named the company's key strengths and weaknesses. The column index, any one of these factors is likely due to its effect on the company's strategic position, the weight of a (very important) to zero (trivial) we have. Values in the column are the experts that the average coefficients. Normalized numbers, the coefficients are written in columns. The rank column, each factor and the management response to the four points (very good) to one (very poor) have chosen. Identified the strengths, the strengths is excellent, and the four stars is a typical power rating of three and also identified weaknesses, it is a common weakness of rank two, and if they have a weakness to a critical level have. The column scores are multiplied by the weight of each factor in the rating factor to obtain a weighted score. The total weighted score of 2.83 , which is the sum of all points hitting rhythmic internal factors, we've earned. The sum of the weighted scores of 2.5 and 2.83 shows that the strengths outweigh the weaknesses are.

\subsection{Evaluation of External Factors}

Studies show, 23 opportunities and 17 threats in the organization(as shown in table 2 given in Appendix). The following matrix is the same as the previous internal factors evaluation matrix, the outcomes of the company's executives and experts. To determine the weight and rank as before we act. Here's the scoring column for the opportunities as well as the strengths and weaknesses of the threats we act. This matrix is based on the weighted sum of points, which is larger than 2.5 and 3.02 shows that the company, the opportunities outweigh the threats are.

\subsection{Exploiting Strategies Using Clustering Results}

In this stage, after identifying the strength and weakness factors, opportunities and organizational threats and valuing each factor using the opinions of experts in organization which are determined based on the rate of importance, we examine the clustering. Our work is based on the method of labeling 6 . We clustered each factor separately and then put them in 4 groups (A, B, C, D) and finally we put the identified factors in similar group in one cluster. This stage, we applied K-Means Method and software of MATLAB, which has been explained in chapter 3 , the results and the outputs from this clustering are similar to those from clustering, which are to extract the strategy, which is reported below.

First Cluster

(S45,S46,S47,S42,S39,S36,S34,S30,S26,S27,S23,S24,S2 1,S16,S17,S11,S9,S5,S6,S7,S3),(W1,W2,W3,W5,W8,W10, $\mathrm{W} 12, \mathrm{~W} 14, \mathrm{~W} 15),(\mathrm{O} 1, \mathrm{O} 3, \mathrm{O} 4, \mathrm{O} 8, \mathrm{O} 10, \mathrm{O} 12, \mathrm{O} 13, \mathrm{O} 15, \mathrm{O} 22),($ $\mathrm{T} 3, \mathrm{~T} 8, \mathrm{~T} 9, \mathrm{~T} 10, \mathrm{~T} 11, \mathrm{~T} 12, \mathrm{~T} 15)$

Second Cluster

(S8,S10,S12,S25,S28,S32,S37,S43,S44),(W4,W24),(O9, O14,O16,O18,O19,O21),(T1,T7,T16)

\section{Third Cluster}

(S4,S13,S14,S15,S18,S20,S22),(W6,W7,W9,W11,W13, W16,W17,W29,W31,W32,W35,W36,W38,W39,W40),(O5, $\mathrm{O} 6, \mathrm{O} 11, \mathrm{O} 17, \mathrm{O} 20),(\mathrm{T} 2, \mathrm{~T} 4, \mathrm{~T} 5, \mathrm{~T} 6, \mathrm{~T} 13, \mathrm{~T} 14)$

Fourth Cluster

(S1,S2,S19,S29,S31,S33,S35,S38,S40,S41),(W18,W19, W20,W21,W22,W23,W25,W26,W27,W28,W30,W33,W34 )$,(\mathrm{O} 2, \mathrm{O} 7),(\mathrm{T} 17)$

Now, after clustering the above categories and we classified them to extract the best strategy from each cluster.

At this stage, using the results obtained from the cluster, we examinethe outlook for the overall strategy of the organization.

\section{Strategies from cluster 1}

ST1: reengineering posts working with the education and skills of the workforce preparation with existing information systems to improve efficiency

ST2- to activate the educational cores and to culturalize in order to cooperate and help to increase the organizational growth based on effective human force

ST3: identifying new markets and increased competition and marketing department to develop and adopt appropriate marketing strategies

\section{Strategies from cluster 2}

ST1: a comparative study of the leading modeling agencies in the same geographic area covered marketing

ST2: optimization of transportation due to having efficient manpower and equipment

\section{Strategies from the cluster 3}

ST1: providing long-term development projects focused on qualitative expansion of physical facilities and manpower Strategy from cluster 4

ST1: a structure built for receiving comments and suggestions of the staff and the

ST2: deployment of modern approaches to pricing discounts, bulk ordering, forecasting and costing factors for increased profitability

ST3: Master Plan in line with tacit knowledge management personnel (with experience)

\section{Discussions}

In this stage, using the compiled questionnaires, and using the opinions of the organizational experts, we examined the one-by-one comparison of all strategies, either those are available in organization or those are presented by offered method. Using cost performance index Earned value from a technique we studied how to score and prioritize each of the strategies. Feedback consists of three pillars: a description of the proposed strategy, the strategy and column privilege description. Those strategies that have high priority and importance are scored 100 and those that have less importance scored 1.

In order to assess strategies are derived and its performance compared with existing strategies, cost performance index method is used. This index is used to 
show the proportion of planned cost for performed job and consumed cost, which is known as performance coefficient of system.

Cost Performance Index: $(\mathrm{CPI}=\mathrm{EV} / \mathrm{AC}$ Cost Performance Index)

After collecting the opinion polling forms from managers and organizational experts and averaging the yield scores, the gained score will be determined for intended strategy. Now, after comparing each strategy we discuss how to value them using Cost Performance Index.

After reviewing the above table the following results are obtained:

7 Strategies among 9 strategies identified in organization got the higher score than existing strategies.

Two strategies from the existing strategies got higher scores: whereas, managers of organization score the strategies based on the importance and their closeness to the organizational purposes and missions. These two strategies available in organization have more closeness to their policies. Because industries like cement believe that to identify the customers and new markets are performed by customers, because for customers the distance is so important and also presenting deduction in special conditions (as said in chapter 3 ) will be done and thus, these two identified categories are less important than the equaled one in above table.

Due to the high scores in the areas of our strategy are as follows:

1. To achieve maximum production and sales

2. Post reengineering work with the education and skills of the workforce preparation with the help of the information systems with the aim of improving productivity

3. Activate core educational and cultural cooperation in order to contribute to organizational growth synergies of efficient manpower.

4. Provide marketing and sales policies to maintain market share

5. Comparative study leading to similar organizations modeled upon the field of marketing geographical

6. Optimize the transportation of personnel and equipment having

7. Provide long-term development plan with a focus on quality and expansion of physical facilities and manpower

8. Structure and system of internal proposals for obtaining the views of its staff

9. Tacit Knowledge Management Plan in line with agency personnel (with experience)

Table 3. Opinion Polling of Experts in Organization

\begin{tabular}{|c|c|c|c|c|c|}
\hline No & Suggested strategies & Score & No & Existing strategies & Score \\
\hline 1 & $\begin{array}{l}\text { Post reengineering work with the education and skills } \\
\text { of the workforce preparation with the help of the } \\
\text { information systems with the aim of improving } \\
\text { productivity }\end{array}$ & & 1 & $\begin{array}{l}\text { The strategies } \\
\text { To achieve maximum production and sales }\end{array}$ & \\
\hline 2 & $\begin{array}{l}\text { Activate core educational and cultural cooperation in } \\
\text { order to contribute to organizational growth synergies } \\
\text { of efficient manpower }\end{array}$ & & 2 & $\begin{array}{l}\text { Marketing and export development in Central } \\
\text { Asian countries }\end{array}$ & \\
\hline 3 & $\begin{array}{l}\text { Identify new markets and increased competition, } \\
\text { marketing and research and development units to } \\
\text { adopt appropriate marketing strategies }\end{array}$ & & 3 & Development of Sales Engineering & \\
\hline 4 & $\begin{array}{l}\text { Comparative study leading to similar organizations } \\
\text { modelled upon the field of marketing geographical }\end{array}$ & & 4 & $\begin{array}{l}\text { Increase the number of customers and the } \\
\text { development of micro capillary network in the } \\
\text { market }\end{array}$ & \\
\hline 5 & $\begin{array}{l}\text { Optimize the transportation of personnel and } \\
\text { equipment having efficient }\end{array}$ & & 5 & $\begin{array}{l}\text { Provide marketing and sales policies to maintain } \\
\text { domestic market share }\end{array}$ & \\
\hline 6 & $\begin{array}{l}\text { Provide long-term development plan with a focus on } \\
\text { quality and expansion of physical facilities and } \\
\text { manpower }\end{array}$ & & 6 & Cement Transport Network Development & \\
\hline 7 & $\begin{array}{l}\text { Structure and system of internal proposals for } \\
\text { obtaining the views of its staff }\end{array}$ & & & & \\
\hline 8 & $\begin{array}{l}\text { Deployment of modern approaches to pricing } \\
\text { discounts, bulk ordering, forecasting and costing } \\
\text { factors for increased profitability }\end{array}$ & & & & \\
\hline 9 & $\begin{array}{l}\text { Tacit Knowledge Management Plan in line with } \\
\text { agency personnel (with experience) }\end{array}$ & & & & \\
\hline
\end{tabular}


Table 4. Earned value comparisons

\begin{tabular}{|c|c|c|}
\hline Achieved score & Existing strategies & Identified strategies \\
\hline $67.5 / 7.5=9$ & Development of Sales Engineering & $\begin{array}{l}\text { Post reengineering work with the education } \\
\text { and skills of the workforce preparation with the } \\
\text { help of the information systems with the aim of } \\
\text { improving productivity }\end{array}$ \\
\hline $75 / 7.5=10$ & Development of Sales Engineering & $\begin{array}{c}\text { Activate core educational and cultural } \\
\text { cooperation in order to contribute to } \\
\text { organizational growth synergies of efficient } \\
\text { manpower }\end{array}$ \\
\hline $40 / 50=0.8$ & $\begin{array}{l}\text { Provide marketing and sales policies to } \\
\text { maintain market share }\end{array}$ & $\begin{array}{c}\text { Identify new markets and increased } \\
\text { competition, marketing and research and } \\
\text { development units to adopt appropriate } \\
\text { marketing strategies }\end{array}$ \\
\hline $55 / 40=1.37$ & $\begin{array}{l}\text { Marketing and export development in Central } \\
\text { Asian countries }\end{array}$ & $\begin{array}{c}\text { Comparative study leading to similar } \\
\text { organizations modelled upon the field of } \\
\text { marketing geographical }\end{array}$ \\
\hline $85 / 65=1.31$ & Cement Transport Network Development & $\begin{array}{l}\text { Optimize the transportation of personnel and } \\
\text { equipment having }\end{array}$ \\
\hline $85 / 22.5=3.38$ & $\begin{array}{c}\text { Increase the number of customers and the } \\
\text { development of micro capillary network in the } \\
\text { market }\end{array}$ & $\begin{array}{l}\text { Provide long-term development plan with a } \\
\text { focus on quality and expansion of physical } \\
\text { facilities and manpower }\end{array}$ \\
\hline $27.5 / 82.5=0.33$ & Development of Sales Engineering & $\begin{array}{l}\text { Structure and system of internal proposals for } \\
\text { obtaining the views of its staff }\end{array}$ \\
\hline $27.5 / 82.5=0.33$ & To achieve maximum production and sales & $\begin{array}{l}\text { Deployment of modern approaches to pricing } \\
\text { discounts, bulk ordering, forecasting and } \\
\text { costing factors for increased profitability }\end{array}$ \\
\hline $75 / 7.5=10$ & Development of Sales Engineering & $\begin{array}{l}\text { Tacit Knowledge Management Plan in line } \\
\text { with agency personnel (with experience) }\end{array}$ \\
\hline
\end{tabular}

\section{Conclusions}

In this research, after studying and examining and interviews in organization in order to encode the strategies, the results are achieved in the form of mathematical clusters to purify the SWOT factors in process of strategic planning. The exited strategies from the proposed method include the following advantages:

- Ability to implement strategies in the functional units due to the transparent nature of the strategies

- Macro-strategy clustering method to transform strategy into operational plans that are lacking in order to analyze the implementation of the strategy for success.

- Placement in a cluster of similar factors, and helps develop better strategies to be aligned on a bunch of factors

The results indicate that mathematical clustering plays an effective role to identify all effective factors in organization and to classify them in order to compile optimum strategies and also achieving techniques and values to get to this effective case. When evaluating the performance, we discussed and compared the identified strategies in organization and finally the output is strategies required for organization. Choosing the best strategy to improve the organization's strategic planning process and the superior strategy and techniques through the process described above, have been obtained.

\section{Appendix}

Table 1. Internal Factors Evaluation Matrix

\begin{tabular}{|c|c|c|c|c|}
\hline \multirow{2}{*}{ No } & Internal Factors & \multirow{2}{*}{ Coefficient } & \multirow{2}{*}{ Rank } & \multirow{2}{*}{ Score } \\
\cline { 2 - 4 } & Strengths & 0.04 & 4 & 0.16 \\
\hline 1 & S1: Profitability & 0.03 & 4 & 0.013 \\
\hline 2 & S 2: having the knowledge within an organization and constantly growing & 0.01 & 3 & 0.03 \\
\hline 3 & S3: technical knowledge up to date & 0.02 & 4 & 0.08 \\
\hline 4 & S4: ensuring customer satisfaction with minimal complaints and high production efficiency. & 0.01 & 3 & 0.03 \\
\hline 5 & S5: Send daily reports to senior management and management of Sydkoo & 0.01 & 3 & 0.03 \\
\hline 6 & S6: Certification to ISO 9001, ISO 18001, ISO 14001 quality system development & 0.01 & 3 & 0.03 \\
\hline 7 & S7: The process control with the dedicated instructions & 0.02 & 3 & 0.06 \\
\hline 8 & S8: organizational structure & 0.01 & 3 & 0.03 \\
\hline 9 & S9: having a team of research and development & 0.01 & 4 & 0.04 \\
\hline 10 & S10: new product development capability and production & & & \\
\hline
\end{tabular}




\begin{tabular}{|c|c|c|c|c|}
\hline 11 & $\begin{array}{l}\text { S11: The benefit of appropriate equipment for production and testing of products compared to } \\
\text { competitors }\end{array}$ & 0.01 & 3 & 0.03 \\
\hline 12 & S12: a fully equipped laboratory in the cement industry in the province & 0.01 & 4 & 0.04 \\
\hline 13 & S13: clinker production capacity and keep them in stock! & 0.02 & 4 & 0.08 \\
\hline 14 & S14: higher quality product than competitors & 0.02 & 4 & 0.08 \\
\hline 15 & S15: geographic scope for export of goods manufactured & 0.02 & 4 & 0.08 \\
\hline 16 & S16: space and facilities equipped and spacious building & 0.01 & 3 & 0.03 \\
\hline 17 & S17: Communication company with sales channels & 0.01 & 3 & 0.03 \\
\hline 18 & S18: High market share, product quality and product diversity & 0.02 & 4 & 0.08 \\
\hline 19 & S19: Coordination with company policy, government policy & 0.03 & 4 & 0.12 \\
\hline 20 & S20: credit top brand with customers & 0.02 & 4 & 0.08 \\
\hline 21 & S21: The effective marketing and market segmentation diversified real & 0.01 & 3 & 0.03 \\
\hline 22 & S22: Previous customer satisfaction and loyalty of their relative performance & 0.02 & 4 & 0.08 \\
\hline 23 & S23: good relationships and access to new technologies & 0.01 & 3 & 0.03 \\
\hline 24 & S24: having the proper information systems and communication software & 0.01 & 3 & 0.03 \\
\hline 25 & S25: In a more practical application of new technology and organizational communication & 0.02 & 3 & 0.06 \\
\hline 26 & S26: Equipped with technology systems, enterprise IT organizations have lead to the same production & 0.01 & 3 & 0.03 \\
\hline 27 & S27: having a high level of knowledge within an organization and constantly growing & 0.01 & 3 & 0.03 \\
\hline 28 & S28: having expert-level human resources executives and experts & 0.01 & 4 & 0.04 \\
\hline 29 & S29: various educational services & 0.05 & 3 & 0.15 \\
\hline 30 & S30: adequate physical facilities and convenient location for training & 0.01 & 3 & 0.03 \\
\hline 31 & S31: Benefit from experienced faculty & 0.05 & 4 & 0.02 \\
\hline 32 & S32: manpower capabilities & 0.01 & 4 & 0.04 \\
\hline 33 & S33: the relevance of education for the majority of corporate executives Posts & 0.05 & 3 & 0.15 \\
\hline 34 & S34: enforcement mechanisms for granting representation in the target market & 0.01 & 3 & 0.03 \\
\hline 35 & S35: the young and strong exports and sales expert & 0.05 & 4 & 0.02 \\
\hline 36 & S36: promoting safety and health professional & 0.01 & 3 & 0.03 \\
\hline 37 & S37: improving labour productivity & 0.02 & 3 & 0.06 \\
\hline 38 & S38: experiences and current director of the Company & 0.05 & 4 & 0.02 \\
\hline 39 & S39: transport and port facilities in the Port of Amir Abad & 0.01 & 3 & 0.03 \\
\hline 40 & S40: offering discounts to buyers of the 1000 & 0.05 & 3 & 0.15 \\
\hline 41 & S41: Internet facilities managed by different organizational units & 0.05 & 3 & 0.15 \\
\hline 42 & S42: Increase customer satisfaction over the past year & 0.01 & 3 & 0.03 \\
\hline 43 & $\begin{array}{l}\text { S43: construction of more green space and using more advanced equipment to reduce environmental } \\
\text { pollution }\end{array}$ & 0.01 & 4 & 0.04 \\
\hline 44 & S44: Energy efficiency in thermal power plants using furnace control & 0.01 & 4 & 0.04 \\
\hline 45 & S45: correlation with the degree of care & 0.01 & 3 & 0.03 \\
\hline 46 & S46: Use of force employed by the younger and more up to date knowledge in the company of units & 0.01 & 3 & 0.03 \\
\hline 47 & S47: Head of increasing degree in various units and individuals in recent years. & 0.01 & 3 & 0.03 \\
\hline \multicolumn{5}{|c|}{ Weaknesses } \\
\hline 48 & W1: poor reception quality standards by unit & 0.01 & 2 & 0.02 \\
\hline 49 & $\begin{array}{l}\text { W2: Lack of adequate communication between the goals and objectives of the quality system } \\
\text { strategies }\end{array}$ & 0.02 & 1 & 0.02 \\
\hline 50 & W3: lack of job description and job requirement for positions as written in units & 0.01 & 2 & 0.02 \\
\hline 51 & W4: lack of funding for segregated units partially & 0.02 & 2 & 0.04 \\
\hline 52 & W5: Not the time for noncompliance projects & 0.01 & 2 & 0.02 \\
\hline 53 & W6: lack of participation in decision making in organizations & 0.01 & 1 & 0.01 \\
\hline 54 & W7: lack of management commitment and vision of the organization & 0.01 & 1 & 0.01 \\
\hline 55 & W8: the lack of a suitable organizational structure & 0.01 & 2 & 0.02 \\
\hline 56 & W9: poor recruitment & 0.05 & 2 & 0.01 \\
\hline 57 & W10: not the administrators for management review meeting & 0.01 & 2 & 0.02 \\
\hline 58 & W11: lack of familiarity with the system of quality management courses for newcomers & 0.01 & 2 & 0.01 \\
\hline 59 & W12: weak institutional activities & 0.01 & 2 & 0.02 \\
\hline 60 & W13: lack of attention to the task and organizational forms & 0.05 & 2 & 0.01 \\
\hline 61 & W14: failure to allocate an appropriate number of labour units & 0.01 & 2 & 0.02 \\
\hline 62 & W15: the reluctance of managers to improve organizational processes & 0.01 & 2 & 0.02 \\
\hline 63 & W16: the lack of a reasonable team to conduct internal audits & 0.05 & 2 & 0.01 \\
\hline 64 & W17: weak organizational units to fill out forms for non-compliance & 0.05 & 2 & 0.01 \\
\hline 65 & W18: shortcomings in the company's R \& D and innovation & 0.01 & 2 & 0.02 \\
\hline 66 & $\begin{array}{l}\text { W19: Lack of performance management systems within an organization to assess and improve } \\
\text { performance }\end{array}$ & 0.02 & 1 & 0.02 \\
\hline 67 & W20: low relative strength and integrity of the structure & 0.02 & 1 & 0.02 \\
\hline 68 & W21: the lack of an integrated information system & 0.01 & 2 & 0.02 \\
\hline
\end{tabular}




\begin{tabular}{|l|c|c|c|c|}
\hline 69 & W22: restrictions on sales to customers less than 1,000 in Sales Dept & 0.01 & 2 & 0.02 \\
\hline 70 & W23: restrictions on sales to buyers in over 1,000 units in trade and sale unit & 0.01 & 2 & 0.02 \\
\hline 71 & W24: Marketing to identify weaknesses in the foreign market & 0.02 & 2 & 0.04 \\
\hline 72 & W25: lack of proper follow up with survey forms & 0.01 & 2 & 0.02 \\
\hline 73 & W26: Not Specified Low prices for manufactured products to attract customers & 0.01 & 2 & 0.02 \\
\hline 74 & W27: a comprehensive review of the application for restoration of lost customers & 0.02 & 1 & 0.02 \\
\hline 75 & W28: lack of clear understanding of the organization's strategic marketing & 0.01 & 2 & 0.02 \\
\hline 76 & W29: rejection of organizational culture on IT & 0.05 & 2 & 0.01 \\
\hline 77 & W30: lack of support from senior director of information technology & 0.01 & 2 & 0.02 \\
\hline 78 & W31: inhibition of the IT organization and increase paperwork & 0.05 & 2 & 0.01 \\
\hline 79 & W32: lack of attention to organizational strategy & 0.01 & 1 & 0.01 \\
\hline 80 & W33: lack of attention to the management of information systems for decision-making & 0.01 & 2 & 0.02 \\
\hline 81 & W34: poor infrastructure, lack of information and flexibility & 0.01 & 2 & 0.02 \\
\hline 82 & W35: failure to properly allocate organizational posts & 0.05 & 2 & 0.01 \\
\hline 83 & W36: risks identified in unit sales due to young force available & 0.01 & 2 & 0.01 \\
\hline 84 & W37: lack of access to Oldest forces to use their experience & 0.05 & 1 & 0.02 \\
\hline 85 & W38: Lack of efficacy of training for participants by teaching unit & 0.05 & 2 & 0.01 \\
\hline 86 & W39: lack of experts and managers working in a team & 0.05 & 2 & 0.01 \\
\hline 87 & W40: low average levels of factory production units & 0.05 & 2 & 0.01 \\
\hline & Sum of Strengths and Weaknesses & 1 & & 2.83 \\
\hline
\end{tabular}

Table 2. External Factor Evaluation Matrix

\begin{tabular}{|c|c|c|c|c|}
\hline \multirow{2}{*}{ No } & External Factors & \multirow{2}{*}{ Coefficient } & \multirow{2}{*}{ Rank } & \multirow{2}{*}{ Score } \\
\hline & Opportunities & & & \\
\hline 1 & O1: Negotiating with shipping, railroad, trucking companies to reduce logistics costs & 0.02 & 3 & 0.06 \\
\hline 2 & O2: Find the exporting countries, particularly Iraq and Turkmenistan. & 0.02 & 4 & 0.08 \\
\hline 3 & O3: negotiating with local transport companies to reduce cost & 0.02 & 3 & 0.06 \\
\hline 4 & O4: Benchmarking of companies of similar nature & 0.02 & 3 & 0.06 \\
\hline 5 & O5: creating the infrastructure required for the development of the capillary network & 0.03 & 3 & 0.09 \\
\hline 6 & O6: cement composite (composite) & 0.03 & 4 & 0.12 \\
\hline 7 & O7: revenue growth and profitability & 0.01 & 4 & 0.04 \\
\hline 8 & O8: allocating funds towards the development of distribution networks & 0.02 & 3 & 0.06 \\
\hline 9 & O9: Increase the amount of maintenance the system upgrades & 0.01 & 3 & 0.03 \\
\hline 10 & O10:Promotion of Information and Communication Technology and Organization & 0.02 & 3 & 0.06 \\
\hline 11 & O11: Foreign market development and export & 0.03 & 4 & 0.12 \\
\hline 12 & O12: development, sales and market penetration Civil Engineering Other & 0.02 & 3 & 0.06 \\
\hline 13 & O13: strategic positioning of the company superior cement Neka & 0.02 & 3 & 0.06 \\
\hline 14 & O14: the competing firms in terms of product quality & 0.01 & 3 & 0.03 \\
\hline 15 & O15: high demand of cement in the province & 0.02 & 3 & 0.06 \\
\hline 16 & O16: committed to long-term customers of this company & 0.01 & 3 & 0.03 \\
\hline 17 & O17: near the Caspian countries to export their product. & 0.03 & 4 & 0.12 \\
\hline 18 & $\begin{array}{l}\text { O18: attract customers with higher purchasing power and provide better facilities to them through } \\
\text { discounts }\end{array}$ & 0.01 & 3 & 0.03 \\
\hline 19 & O19: mechanization and automation solution for loading goods by trucks & 0.01 & 3 & 0.03 \\
\hline 20 & O20:availability of raw materials required for cement mines in the province due to its posture & 0.03 & 4 & 0.12 \\
\hline 21 & O21: establishment of province in a location in order to reduce pollution & 0.01 & 3 & 0.03 \\
\hline 22 & O22: Using old tires for fuel use & 0.02 & 3 & 0.06 \\
\hline \multicolumn{5}{|c|}{ Threats } \\
\hline 23 & T1: removal of fuel subsidies and a sharp increase in the price of transport & 0.03 & 1 & 0.03 \\
\hline 24 & T2: reducing the marketability of Golestan & 0.02 & 2 & 0.04 \\
\hline 25 & T3: focus on reducing market sales due to capillary network & 0.01 & 2 & 0.02 \\
\hline 26 & T4: breaking price that they can compete with neighbouring factories & 0.02 & 2 & 0.04 \\
\hline 27 & T5: transportation as a challenge to deliver the product to the place of consumption prices & 0.02 & 2 & 0.04 \\
\hline 28 & T6: more customers tend to buy on price, not quality & 0.02 & 2 & 0.04 \\
\hline 29 & T7: export problems due to crisis & 0.03 & 1 & 0.03 \\
\hline 30 & T8: Consumer products rival cement factories in the province. & 0.01 & 2 & 0.02 \\
\hline
\end{tabular}




\begin{tabular}{|l|r|c|c|c|}
\hline 31 & T9: Resistance shipping companies to change their procedures & 0.01 & 2 & 0.02 \\
\hline 32 & T10: failure to recognize and resist the implementation of cost reduction & 0.01 & 2 & 0.02 \\
\hline 33 & T11: New project aims to create a place of not-poor atmosphere & 0.01 & 2 & 0.02 \\
\hline 34 & T12: reducing occupational accidents to zero. & 0.01 & 2 & 0.02 \\
\hline 35 & T13: The low variability in production & 0.02 & 2 & 0.02 \\
\hline 36 & T14: global trends, governments and institutions with a special cement production towards & 0.02 & 2 & 0.02 \\
\hline 37 & T15: Inappropriate status and development units in the industry & 0.01 & 2 & 0.02 \\
\hline 38 & T16: The slowdown in the housing sector & 0.03 & 1 & 0.03 \\
\hline 39 & T17: Lack of activity in factories producing ready-mixed concrete & 0.03 & 2 & 0.06 \\
\hline & Sum of all the opportunities and threats & 1 & & 3.02 \\
\hline
\end{tabular}

\section{REFERENCES}

[1] Richard L. Wexelblat, N. Srinivasan, The Department of the Treasury, 1111 Constitution Ave., SW, Washington DC 20224, USA Information \& Management 35 (1999) 265 282

[2] E.D. Meredith, R.D. Forest, R.D. Fred, The quantitative strategic planning matrix applied to a retail computer store, The Coastal Business Journal 8 (1) (2009) 42-52

[3] Hasan Hosseini Nasab, Abbas S. Milanib, An improvement of quantitative strategic planning matrix using multiple criteria decision making and fuzzy numbers, Applied Soft Computing 12 (2012) 2246-2253

[4] A.C. Hax, N.S. Majluf, The Strategy Concept and Process, Prentice \pm Hall, New York, 1991.

[5] Y. Wind, V. Mahajan, Design product and business portfolio, Harvard Business Review 59(1), 1981, pp. 155 165 .

[6] T. William Chien, Chinho Lin, Bertram Tan, Wen Chuan Lee, A neural networks-based approach for strategic planning, Information \& Management 35 (1999) $357 \pm 364$

[7] Mirkin,B.G.(1996).Mathematicalclassificationandclustering. Dordrecht, TheNetherlands:KluwerAcademicPublishing

[8] L.A. Zadeh, Fuzzy sets, Information and Control 8 (1965) 338-353.

[9] W. Pedrycz, Statistically grounded logic operators in fuzzy sets, Europea Journal of Operational Research (2008), doi:10.1016/j.ejor.2007.12.009.
[10] Walter, B. M., \& Robert, F. M. (1988). Accounting: The basis for business decisions. New York: McGraw-Hill.

[11] Wang,Y.J.,\&Lee,H.S.(2008).Aclustering method to identify representative financialratios.InformationSciences, 178,1087-1097..

[12] Johnson, R. A., \&Wichern, D. W. (1992). Applied multivariate statistical analysis. Englewood Cliffs, NJ: Prentice-Hall

[13] Bandyopadhyay, S., \&Maulik, U. (2002). An evolutionary technique based on Kmeans algorithm for optimal clustering in RN. Information Sciences, 146,221-237

[14] Guoyao, F. (1992). An algorithm for computing the transitive closure of a fuzzy similarity matrix. Fuzzy Sets and Systems, 51, 189-194.

[15] Lee, H. S. (1999). Automatic clustering of business processes in business systems. European Journal of Operational Research, 114, 354-362.

[16] Gooderham, G.,(1998),Debunking The Myths of Strategic Planning,CMA Magazine, Vol .72,Iss. 4,pp. 24-26

[17] Stewart, R., 2007, A framework for the life cycle management of information technology projects: Project IT, 10.1016/j.ijproman.2007.05.013

[18] Yu, H.C., Z.Y. Lee and S.C. Chang, 2002, Using a fuzzy multi-criteria decision making approach to evaluate alternative licensing mechanisms. 10.1016/j.im.2002.12.001

[19] Djamasbi, S., and D. M. Strong, 2007, The effect of positive mood on intention to use computerized decision aids. 10.1016/j.im.2007.10.002 